\title{
SOBRE UN MANUSCRITO ÁRABE HALLADO EN ALCÁZAR DE CONSUEGRA
}

\author{
María de la Concepción VÁZQUEZ DE BENITO \\ Universidad de Salamanca
}

Cuando la Biblioteca del recordado profesor Espinosa ${ }^{1}$ fue legada a la Facultad de Filosofía y Letras de la Universidad de Salamanca, el profesor A. Cabo -a quien deseo desde aquí hacer pública mi gratitudpuso a mi plena disposición, para su estudio y posterior edición, un manuscrito que, redactado en lengua árabe, apareció entre el conjunto de libros de dicho legado.

El manuscrito se halla encuadernado en pergamino, consta de 68 páginas en papel, cuya superficie escrita es de 12 por $10 \mathrm{~cm}$., de autor desconocido, y está inconcluso. Al dorso de la primera tapa se escribe en cifras árabes el $\mathbf{n}^{\mathbf{0}} 168$, y en la primera página, en castellano, "Fragmento de Medicina hallado en Alcázar de Consuegra". Siguen a ésta cuatro páginas en blanco, la quinta está encabezada con el siguiente título redactado en árabe: LIBRO QUE CONTIENE TEMAS CONCERNIENTES A VETERINARIA Y ASUNTOS SEMEJANTES QUE REVISTEN GRAN UTILIDAD. Tras este epigrafe viene la descripción de un medicamento, su caligrafía es distinta a la del resto del texto, mucho más pequeña, magrebí, toda ella en negrita, sin vocalizar, y menos tardía que la caligraffa del resto del manuscrito, el cual está también en grafía de tipo magrebí, de rasgos muy grandes, con encabezamientos en rojo y con expresión de vocales. En suma, una

${ }^{1}$ Por si acaso las nuevas generaciones no le conocen, recordaré que el Prof. Ricardo Espinosa Maeso fue profesor auxiliar de griego en Madrid y, a mediados de la década de los cuarenta, vino como Catedrático de Lengua y Literatura Griegas a esta Universidad de Salamanca, donde se jubiló y vivió aún hasta los 85 años. Me cuenta la Prof. C. Giner que legó un verdadero caudal de bibliografía para conocer la historia de la Universidad de Salamanca del siglo XVI, material que daría importante luz -si se estudiase-sobre esta etapa de la vida de la universidad salmantina. 
caligrafía propia de época tardía, usada ampliamente entre los musulmanes españoles del siglo $\mathrm{XV}$ y entre los moriscos del siglo $\mathrm{XVI}^{2}$.

El manuscrito, como expresa el título, contiene una serie de recetas y normas para el tratamiento de animales; aún así, mezclándose con aquéllas, incluye también un variado número de prescripciones y remedios curativos de enfermedades específicas del ser humano. Es evidente, pues, que tanto por la forma como por el contenido la procedencia del texto es morisca.

El interés del mismo es por otra parte doble. Por un lado, contribuye al conocimiento de la terapéutica empleada por la medicina morisca en la que, como se sabe, la falta de testimonios es grande; por otro, posee el documento también un notable interés língüístico, ya de indole fonética ya léxica, puesto que incluye un buen número de préstamos romances o términos adoptados a través de uso romance de origen griego y latino.

\section{Comentario filológico}

Entre los rasgos más sobresalientes se puede destacar que las alteraciones vocálicas que en él aparecen referidas a la pronunciación clásica son numerosas en cuanto a alargamiento, abreviación, cambio, supresión o aparición de vocales. En efecto, se introducen alargamientos o acortamientos sin ajustarse a un criterio uniforme, algún caso de imäla, y se escribe sukūn al final de muchos términos ya sean nominales $o$ verbales. Asimismo se pone tas $d i d$ arbitrariamente, generalmente sobre mim a comienzo de palabra e igualmente sobre wāw o läm, a la

${ }^{2}$ Ron Barkai, quien asimismo ha hecho el estudio y edición de un texto de medicina morisca del siglo XVI existente en la B.N. de Madrid (caja 18.585 XXI) descrito como "Fragmento de un formulario farmacéutico", 11 fols. (en prensa), se refiere al tratado diciendo: "It is nevertheless clear beyond all doubt that this treatise was composed during the decline of the Arabic language among the moriscos. It is written in broken Arabic, full of mistakes, and its vocabulary is highly restricted. Besides these decadent tendencies, the treatise includes a considerable number of words of Castilian-Romance origin-names of diseases, remedies, plants and herbs, articles of clothing, etc. Throughout the text, I identifie 27 words which are indisputable in Arabic, rather than aljamiado... the linguistic acculturation of de moriscos, as evidenced by the infiltration of Castilian words into the written Arabic used among morisco medical practitioners"... 
vez que se coloca sobre la vocal. Alif suele ir vocalizada y marcada con hamza cuando ésta no deberfa expresarse, y al contrario. No se expresa hamza cuando sí sería adecuado su expresión. La $t a ̈$ ' marbüta frecuentemente se escribe $(h)$ en lugar de $(t)$. Son abundantes también las palabras que se parten al final de línea o que se escriban también las vocales entre el cuerpo de las letras y sus correspondientes puntos diacríticos, e igualmente fatha entre la letra y el tašstd.

A.1. Es frecuente también hallar faltas de ortografia o intercambios. Asi:

Bā' por nūn (qa'rỉb) hendidura

Tâa' por ta $\bar{a}^{\prime}$ (taylūla) gabarro

Tầ' por țā' (qanūt) canuto; (mastaka) almáciga

Tã' por ḍād (ŷarāt) jarado, tumor en el corbejón de la bestia

Tà' por y $\bar{a}^{\prime}$ (bantat) ciñe

Hă' por ŷìm (harāt) jarado, tumor en el corbejón

Hă’ por hamza (hayḍarānī) sal gema

Däl por rā' (dahșa) empedradura; (dahqa) conducta

Dāl por dāl (balāđar) anacardia

Rā' por dāl (rahsa) despeadura

Zãy por ḍāl (aza) (zarajti) acederaque

Sīn por Zāy (kasbūr) coriandro

Sīn por șād (rahsa) despeadura; (sabbāṭ) zapato; (sawf) lana; (inŷās) ciruelo; (dahsa) empedradura; (mastaka) almáciga; (yasīr) llega a ser

Šĩn por șād (inȳāš) ciruelo

Ṣād por sīn (dajṣ̂) foradura; (raṣ') pata; (dājiṣatayn) junturas de tarso y metatarso

Ḍād por dāl (harḍun) camaleón; (ḥayḍarān) sal gema

Dād por șād (raqụa) galope

Țâ' por tā'(ratam) retama

'Ayn por gayn (raṣ') pata

Gayn por jā' (dags) dájaso o clavo pasado

Qãf por kāf (qibrìt) azufre; (qarabsi) apio

Qāf por gayn (maql) torzón 
Kāf por qāf (salk) acelga; (kasbür) coriandro; (Bukrāt) Hipocrates; (akhal) seca

Lām por rā' ('ar'āl) enebro

Alif tawīa por alif maqșūra (jușā) cojones; (miq̨lā) sartén; (qulā) freir;

(tarā) veas; (hummā) fiebre...

Yã' por hamza (kāyin) existente; (gāyit) heces

Yà' por nün (hayḍarānī) sal gema

Finalmente algún caso de metátesis:

(hinaq) por (haqn) clister y (junāqiya) por (huqua) clister. El demostrativo alterna su escritura con forma plena y abreviada e igualmente la asimilación (aratta) con (aradta) y (araddat).

En cuanto a la determinación, la marca que presenta el texto es la alternancia (al)/(il), no acaeciendo la elisión de la vocal tras otra.

El caso se utiliza mal. No se pone la marca (i) para el genitivo ni la marca (a) para el predicado de (kāna) o para el acusativo.

Los sustantivos en dual conciertan con plural o el plural de irracionales concierta con masculino o el femenino con dual. Tampoco concierta el calificativo con el nombre.

$\mathrm{La}(\mathrm{n})$ de dual a veces no se pierde en anexión.

Se confunde (in) condicional con (an) completivo.

El verbo a comienzo de frase y con sujeto explícito se pone en plural y además suele llevar el prefijo (t). Por último alterna la construcción de (ị̣āfa) con el uso de la preposición (mata), (matā), (matā'a) o (mî).

A.2. En cuanto al léxico, aparecen bastantes romancismos ya como sinónimos del término árabe, ya solos, e incluso algunos morazabis$\operatorname{mos}^{3}$. A saber:

AṬRŨN (BURŨM) BROMO

ĀKILA (MANŶAŠ, FIŠTULAŠ) FÍSTULA, MANCHA

${ }^{3}$ Idem. 


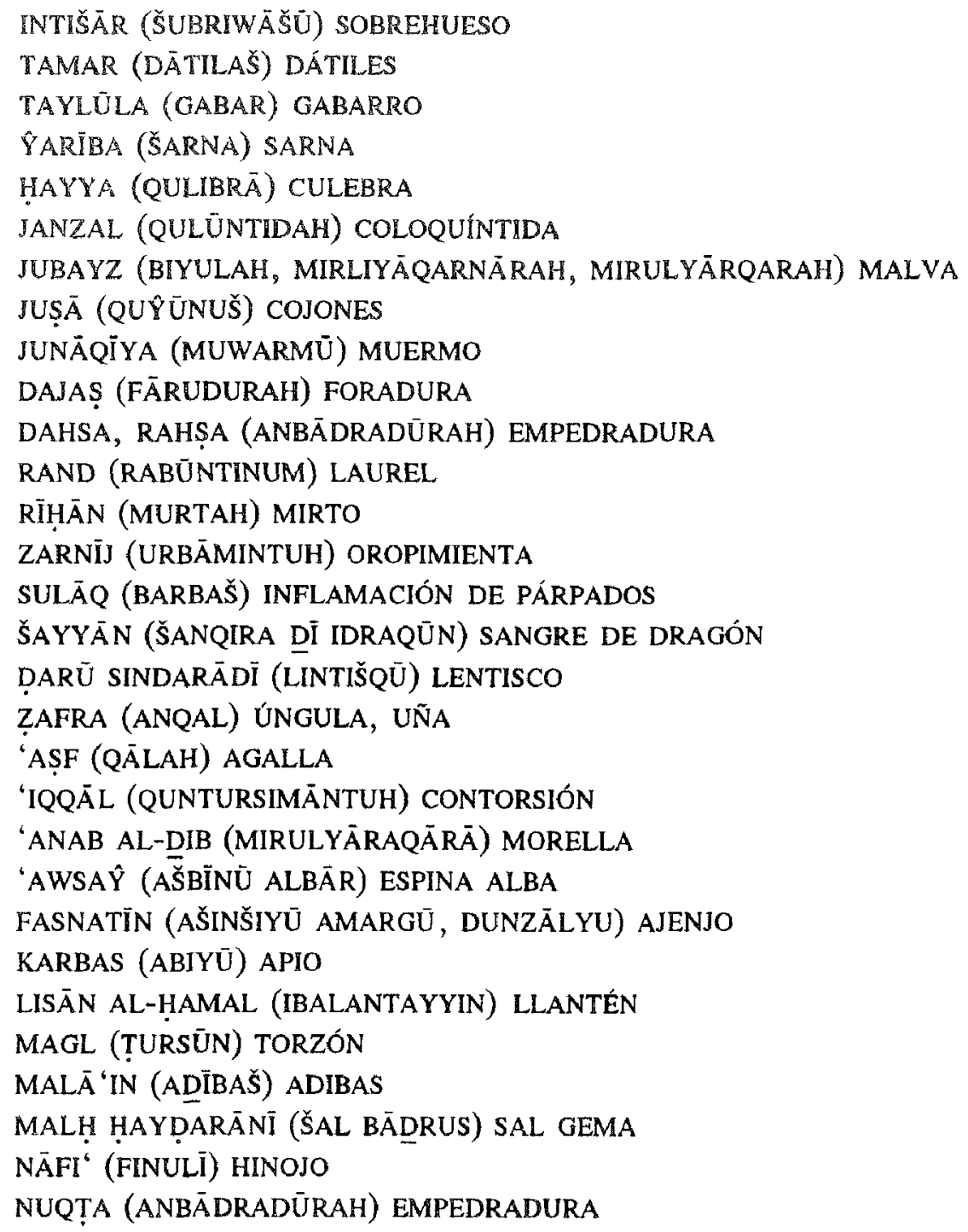

A.3. Términos sólo romances

ABLAN (plantén)

ARMŪ (muermo)

IŠBIRBĀN (esparabán) 


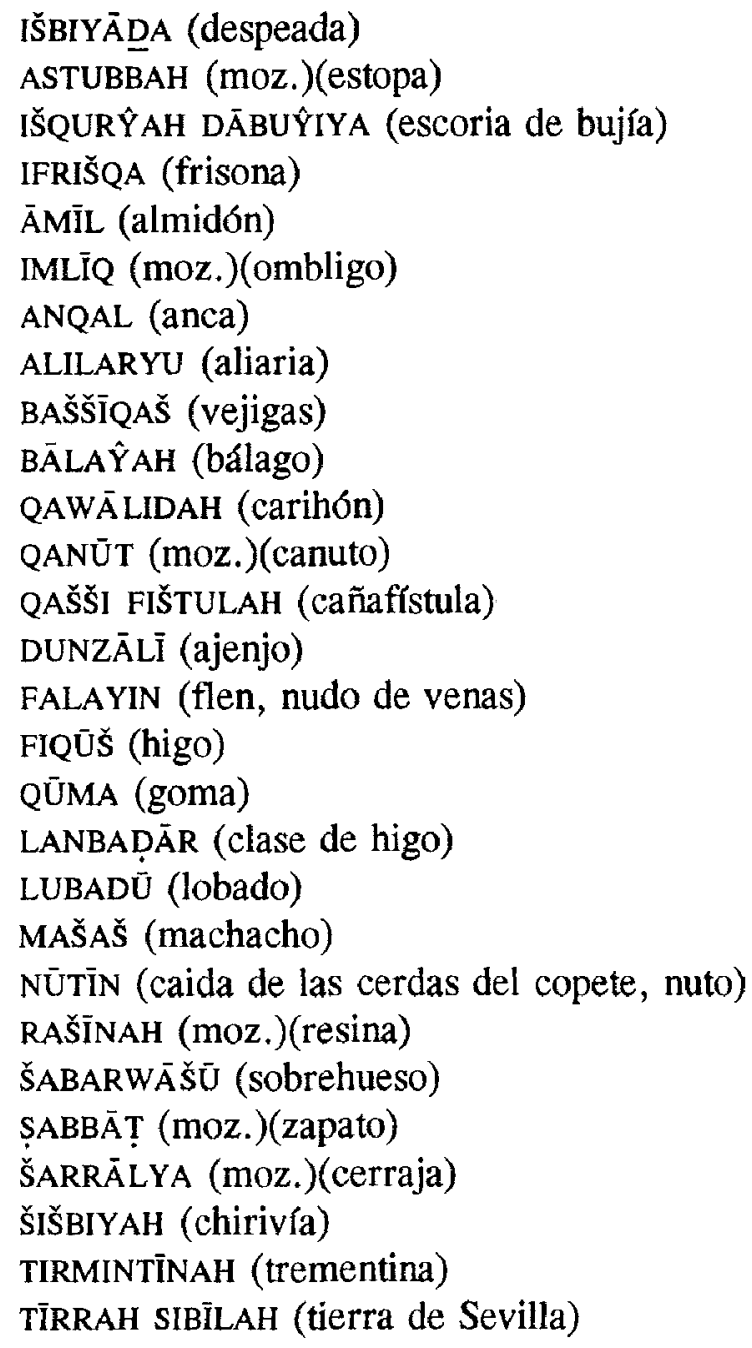

A.4. La transliteración por tanto en caracteres latinos es como sigue:

Consonantismo:
B..... bā'
C..... qāf
Ch.... šin y ŷīm
D.... dâl y dāl 
F..... fă'

G.... gayn, qāf y ९̄im

H..... fă' y wāw

J.... ŷ̀ìn, šin, y yā'

L..... lām

Ll... lām

M.... mìm y nūn

N.... nūn

$\tilde{N} . . . . \quad$ sinn

P.... bā'

Q..... qā̄f

R..... rā'

S..... šinn

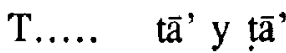

Y..... y $\mathrm{y}^{\overline{\mathrm{a}}}$

Z..... $\sin$

Los grupos consonánticos en comienzo de palabra tienden a disolverse:

BR $>$ buru, bar. DR $>$ idr. FR $>$ ifri. PL $>$ abla. TR $>$ tir. FL $>$ fala .

Vocalismo:

A $>$ a, ă, i. E > ā, i, î, u. I > i, î, u. $O>$ u, $\bar{u}, \bar{a}$, i. $U>$ u, $\bar{u}, a$.

Diptongos:

HUE > wā. MUE > muwa. IA > iyā, ŷah, yah.

El femenino se expresa (ah). El masculino (uh)

A.6. El contenido.

Versa el texto, como hemos dicho, sobre veterinaria y medicina. Los epigrafes concernientes a la primera son: 
La cauterización. La despeadura. El sofoco. La hematuria. Las verrugas. La extirpación de los gusanos de las heridas. El asma y el ahogo. La depilación. La salida del intestino. La debilidad. El pterigion. $\mathrm{La}$ catarata. Las vejigas. Las adivas. El sobrehueso. La enfermedad de la pezuña. El torzón. El lobado. El retortijón. Las heridas. El muermo. El higo. Las grietas de la pezuña. La sentadura. La torcedura. El clister. La sarna. Los beneficios de la alholva. Las sanguijuelas. El engorde del animal. La empedradura. Un ungüento para las grietas de las patas. El esparaván. La despeadura. La cicatrización de las heridas. El mal en los pies de las ovejas. Las pústulas. La inflamación de la boca y del nervio. La fatiga y el dolor de columna.

Los capítulos sobre medicina son los siguientes:

Un medicamento para los ojos. Las verrugas. Las vejigas. La diarrea y el vómito en los niños. La diarrea excesiva. El dolor de cabeza en los niños. Un medicamento para la hernia testicular. El vómito. El vaciamiento de los humores del cerebro. El feto muerto. La lepra. La sangría de las venas. Las heridas con inflamación. La inflamación de pátpados. La enfermedad del hombro. La detención de la hemorragia nasal. El crecimiento del pelo. Las heridas, la mordedura del perro rabioso y la contusión producida por espada o piedras. La disuria. $\mathrm{La}$ sarna. Las escrófulas. La extración de gusanos de las heridas. El enrojecimiento de los ojos. La evacuación de lombrices intestinales. La inflamación de testículos. Las hemorroides y el prúrigo. La extracción de dientes sin instrumento. La eliminación de sanguijuelos de la garganta y de astillas, huesos o espinas. La picadura de escorpión, reptil o cualquier otro animal venenoso. Las grietas en los talones. La disolución de las inflamaciones endurecidas. La curación de contusiones originadas por espada o cuchillo. La inflamación rebelde y la inflamación de piernas. Las clases de sangre. La cicatrización de heridas. La inflamación de venas como consecuencia de sangría. El chancro. Las heridas que generan sangre, las heridas en general y las que supuran. La inflamación del nervio.

Todo ello se presenta de forma desordenada e incompleta respecto a su tratamiento en la medicina y veterinaria árabes, en las que hallamos ciertos paralelismos y antecedentes tanto con el "Libro de Agricultura" 
de Ibn al-"Awwām" como con el "Libro de la almohada" de Ibn Wāfid de Toledos, aunque la única fuente que se cita con profusión a lo largo de todo el texto es Hipócrates.

El tratado incluye asimismo las típicas plegarias moriscas donde se citan a Adán, Eva, Noé, Set e Isaac, personajes usualmente citados por los moriscos en sus plegarias para pedir a Dios perdón por los pecados. Concretamente esto se halla en la rogativa tercera ${ }^{6}$.

También aparecen las supersticiones moriscas que amalgaman las propiamente paganas con otras árabes o judaicas. Así, se indican qué día es mejor para comprar, vender, embarcarse, casarse, edificar, ponerse enfermo, sangrarse, visitar al sultán, etc.

Mediante ciertos procedimientos se pueden adivinar incluso las condiciones de las personas; esto es, según el día de su nacimiento, y también, conocer cuáles son los días fastos y nefastos. Los días de la semana y del mes, influidos por un astro o constelación, tenían ciertas virtudes maravillosas y son a propósito para cosas distintas.

Todo ello se basa en los asertos de $\hat{Y}$ a'far al-Sādiq (148/765), sexto imam de la $\zeta{ }^{\prime} a$-a su muerte precisamente se desgajan las dos principales ramas del si'ismo, el imamismo duodecimano y el ismailismo septimano-, cuya reputación de sabiduría trascendió las fronteras del si ismo, siendo venerado por los propios adeptos de la sunna desde antiguo.

En cuanto a la procedencia del manuscrito, digamos, como dato histórico, que tras la rebelión de las Alpujarras (1568-70), los moriscos granadinos a partir de Noviembre de 1570 fueron conducidos del Reino de Granada hacia Castilla y que los instalados en Alcázar de San Juan y Consuegra procedían del Marquesado del Cenete y Benamuruel ${ }^{7}$. Así

4 Ibn al-'Awwām, «Libro de Agricultura» de Abu Zacaria Iahia Aben Mohamed Ben Ahmed Ebn El Awam, traducido al castellano y anotado por J.A. Banqueri, ed. facsímil del Ministerio de Agricultura, Madrid, 1988.

${ }^{5}$ C. Álvarez de Morales, El Libro de la Almohada de Ibn Wafid de Toledo (Recetario médico árabe del siglo XI), Toledo, 1980.

- Así, cf. P. Longás, Vida religiosa de los moriscos, Madrid, 1915, pág. 167: "Por las vestiduras de Adán ... Por la corona de Eva... Por las cartas de Set... Por la ascención de Enoc al cielo..."

7 A. Domínguez Ortiz y B. Vincent, Historia de los moriscos. Vida y 
pues, el idioma árabe olvidado en Castilla o cuasi, vuelve con la deportación de los granadinos ${ }^{8}$.

Esperamos en un futuro no muy lejano ofrecer la edición del texto árabe con su correspondiente traducción, todo ello ya en un avanzado estado de elaboración, con el propósito de aportar un grano de arena más en el conocimiento de la terapéutica utilizada por los médicos y veterinarios moriscos tan carente de fuentes como se afirma ${ }^{9}$.

tragedia de una minoria, Madrid, 1978, págs. 50-56. B. Vincent, "L'Expulsion des morisques du Royaume de Granada et leur répartition en Castilla (15701571)", Mélanges de la Casa de Velazquez, 6 (1970), págs. 211-246, y "La expulsión de los moriscos del Reino de Granada y su reparto en Castilla", en Andalucía en la Edad Moderna, Granada, 1976, pág. 104. L. García Ballester, Medicina, ciencia y minorfas marginadas, Granada, 1976, pág. 104: "La diáspora de los moriscos granadinos por Castilla, llevó a estas tierras de forma aguda el problema morisco..."

${ }^{8}$ María Jesús Viguera en el Prólogo de Relatos pios y profanos del ms. aljamiado de Urrea de Jalón, de F. Corriente, Zaragoza, 1990, pág. 17 señala: "los moriscos valencianos y granadinos utilizaban la lengua árabe de forma cotidiana, la hablaban, la empleaban en todo tipo de escritos, públicos y privados..." "...frente a moriscos aragoneses y castellanos que habían perdido la lengua árabe, y al perderla, recurrieron al aljamiado, es decir, a escribir la lengua romance que hablaban (castellano con aragonesismos) con grafemas árabes..."

${ }^{9}$ A. Labarta, "Textos para el estudio de la terapéutica entre los moriscos valencianos", Dynamis 1 (1981), págs. 275-31. A. Labarta-C. Barceló, "Nuevas recetas médicas de moriscos valencianos", Dynamis 7.8 (1987-88), págs. 347-354. L. García Ballester, Medicina, ciencia y minorias marginadas, Granada, 1977, págs. 81 y 121: "Quizás sea éste (la terapéutica empleada por los sanadores moriscos) uno de los capítulos más difíciles y complejos del panorama de la medicina entre los moriscos. La dificultad de las fuentes..." 